LA W RENCE LIVERMORE N A TIO NAL LABORATORY

Report on Characterization of U-10 wt.\% Zr Alloy

J. McKeown, M. Wall, L. Hsiung, P. Turchi

March 5, 2012 
This document was prepared as an account of work sponsored by an agency of the United States government. Neither the United States government nor Lawrence Livermore National Security, LLC, nor any of their employees makes any warranty, expressed or implied, or assumes any legal liability or responsibility for the accuracy, completeness, or usefulness of any information, apparatus, product, or process disclosed, or represents that its use would not infringe privately owned rights. Reference herein to any specific commercial product, process, or service by trade name, trademark, manufacturer, or otherwise does not necessarily constitute or imply its endorsement, recommendation, or favoring by the United States government or Lawrence Livermore National Security, LLC. The views and opinions of authors expressed herein do not necessarily state or reflect those of the United States government or Lawrence Livermore National Security, LLC, and shall not be used for advertising or product endorsement purposes.

This work performed under the auspices of the U.S. Department of Energy by Lawrence Livermore National Laboratory under Contract DE-AC52-07NA27344. 


\title{
Report on Characterization of U-10 wt.\% Zr Alloy
}

\author{
March 1, 2012 \\ Submitted to: \\ Professor Sean M. McDeavitt \\ Department of Nuclear Engineering \\ Texas A\&M University \\ College Station, TX 77843
}

Submitted by:

Condensed Matter and Materials Division

Physical and Life Sciences Directorate

Lawrence Livermore National Laboratory

Livermore, CA 94550

Principal Investigator:

Patrice Turchi

Contributing Authors:

Joseph McKeown

Mark Wall

Luke Hsiung

Patrice Turchi 


\section{Overview}

This report summarizes the chemical and structural characterization results for a $\mathrm{U}-10 \mathrm{wt} . \% \mathrm{Zr}$ alloy to be used in an ultra-high burn-up nuclear fuel concept. The as-cast alloy material was received from Texas A\&M University. Characterization and an initial heat treatment of the alloy material were conducted at Lawrence Livermore National Laboratory. The as-received ingot was sectioned for X-ray analysis, metallography, SEM, TEM, and heat treatments, as shown below in Figure 1.

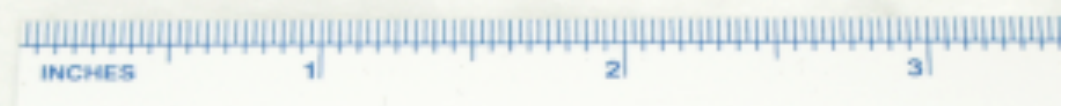

LABORATORY APPARATUS. FURNITURE

SCIENTIFIC INSTRUMENTS \& CHEMICAIS

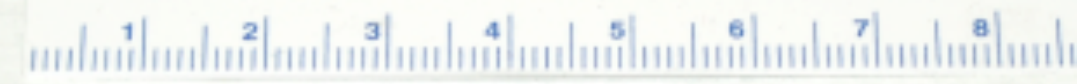

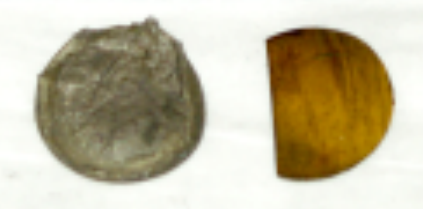

Figure 1: $\quad$ Sectioned as-received U-10Zr ingot.

1. As-Cast U-10Zr Alloy

\subsection{X-ray Diffraction}

A slice of the as-cast U-10Zr alloy was polished to a flat surface. Polishing was performed with progressively finer diamond sheets and finished with a $0.05-\mu \mathrm{m}$ colloidal silica solution. XRD was performed using $\mathrm{Cu} \mathrm{K}_{\alpha}$ radiation. The resulting diffraction pattern is shown in Figure 2. The strong diffraction peaks correspond to uranium (orthorhombic $\alpha$-phase). Small diffraction peaks (arrowed) correspond to the hexagonal $\mathrm{UZr}_{2} \delta$-phase, and there are small peaks that indicate the presence of $\mathrm{ZrO}$. 


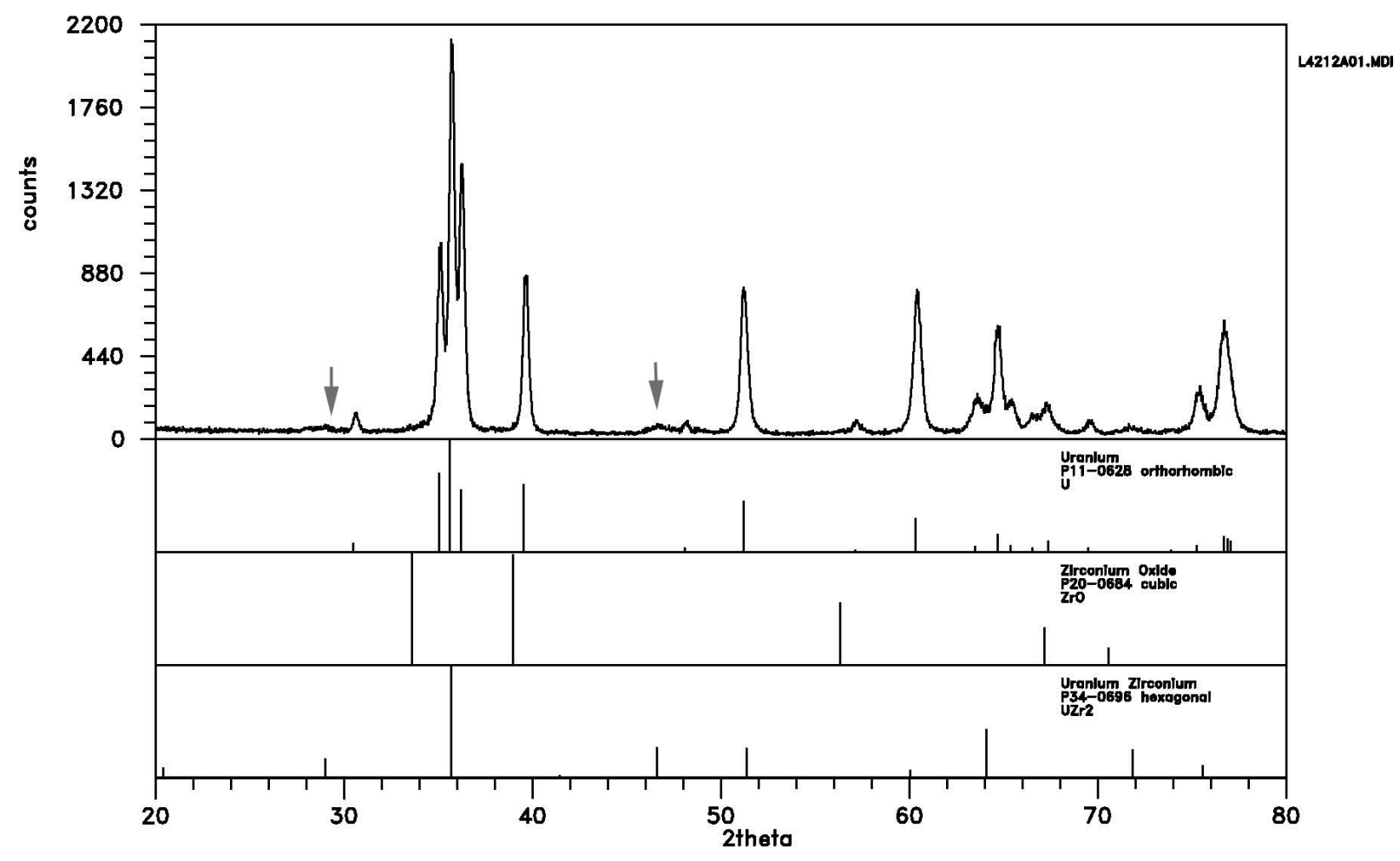

Figure 2: $\quad$ XRD pattern from as-cast U-10Zr sample.

\section{2. $\quad$ Optical Light Microscopy (OLM)}

Optical microscopy was performed on both polished and etched surfaces of the as-cast U-10Zr sample. Figure 3 shows optical micrographs of a polished surface. The sample consists of large grains and primary dendrites scattered throughout. The dendrites, as will be shown subsequently, are composed of $\mathrm{Zr}$ with a small amount of dissolved $\mathrm{U}$. The small, black inclusions are likely oxides or carbides. The number density of dendrites and inclusions increases with distance from the center of the ingot.

After polishing, the surfaces were chemically etched with a $50 \% \mathrm{H}_{3} \mathrm{PO}_{4}$ aqueous solution at $10^{\circ} \mathrm{C}$ and an applied bias of $5 \mathrm{~V}$. Figure 4 shows optical micrographs of an etched surface. Primary dendrites are again clearly visible. Within the large grains there are multiple variants of a structure that is characteristic of martensite plates. There also appears to be a finer structure within these plates. Grain boundaries are also evident. These are likely the grain boundaries present in the high-temperature BCC phase, retained when the sample is cooled. This could be confirmed by in-situ TEM in a heating stage. 
a)

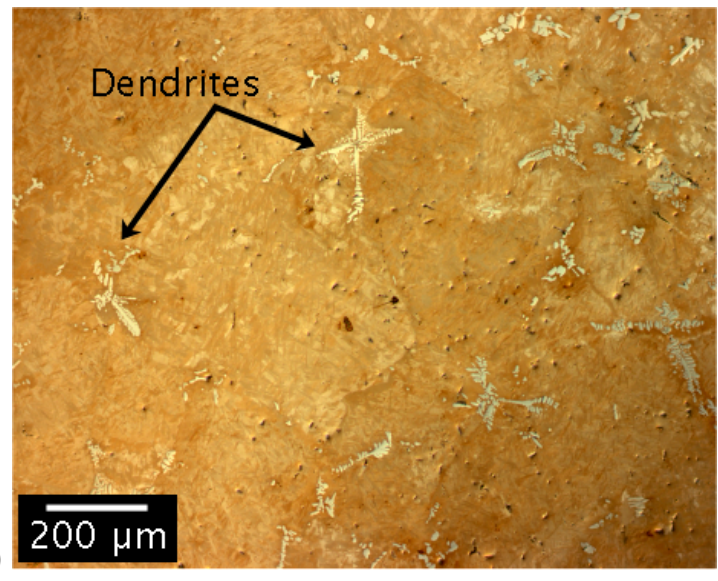

b)

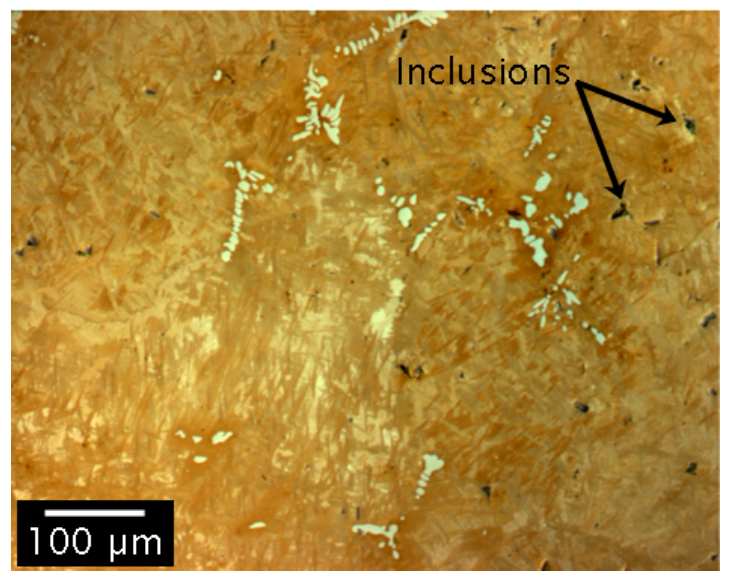

Figure 3: Optical micrographs from a polished surface of the as-cast U-10Zr sample.

a)

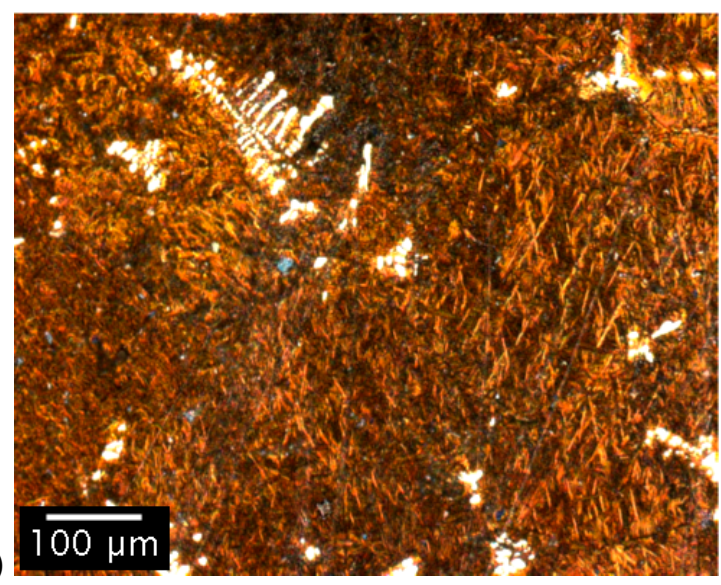

b)

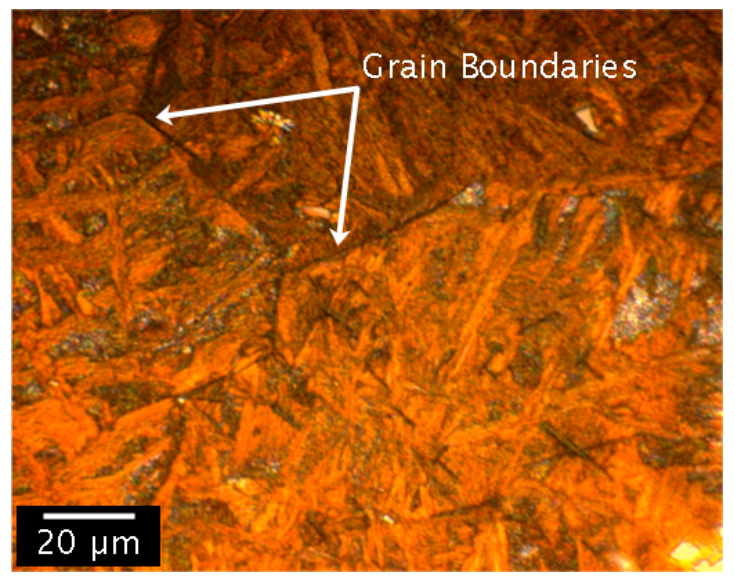

Figure 4: Optical micrographs of a polished and etched surface of the as-cast U-10Zr sample.

\subsection{Hardness Testing}

Microhardness values for the as-cast U-10Zr sample were determined by indentation using the Vickers method with an applied load of $100 \mathrm{gf}$. Figure 5 shows an optical micrograph of the indentations, and the results are summarized in Table 1. The average Vickers hardness (HV) was 435. Converting to other hardness scales give an average Rockwell hardness (HRC) of 44 and an average Knoop hardness (HK) of 452. Hardness values will eventually be measured for all samples after heat treatments to provide a plot of hardness as a function of aging time at some specified aging temperature. 


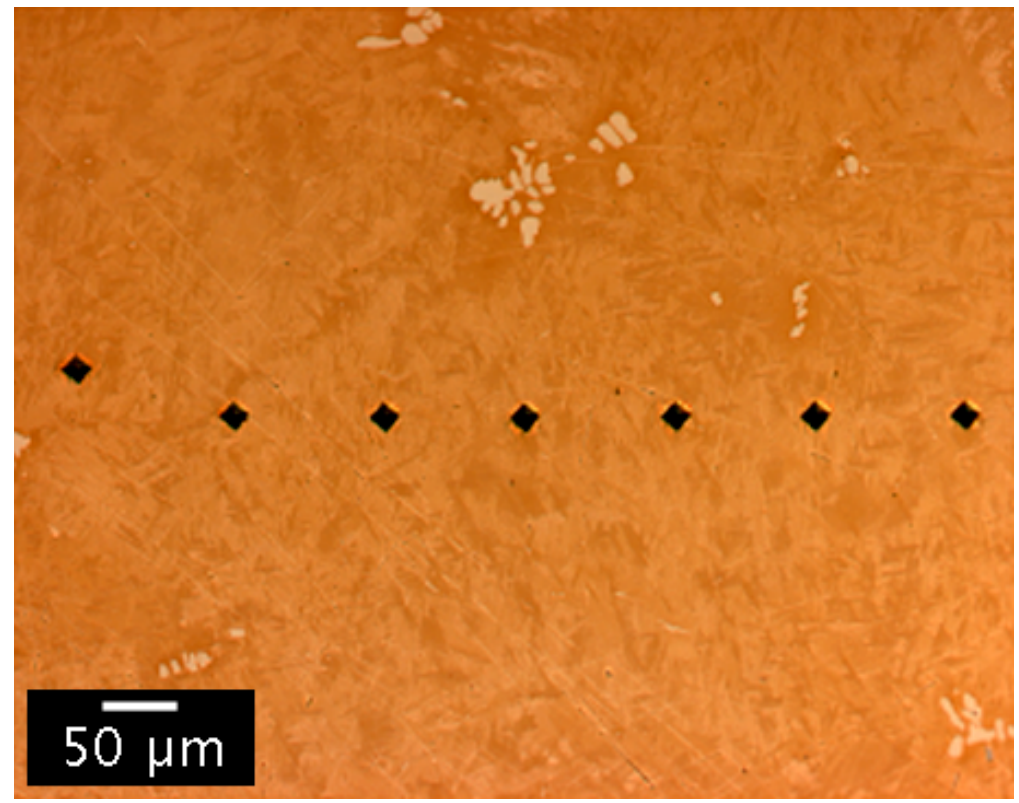

Figure 5: Optical micrograph showing indentations used to calculate microhardness values.

Table 1: $\quad$ Measured microhardness values.

\begin{tabular}{|c|c|c|c|c|c|c|c|}
\hline & $\mathbf{1}$ & $\mathbf{2}$ & $\mathbf{3}$ & $\mathbf{4}$ & $\mathbf{5}$ & $\mathbf{6}$ & Tot/Avg \\
\hline D1* $(\boldsymbol{\mu m})$ & 20.61 & 20.43 & 20.35 & 19.74 & 20.26 & 20.43 & 20.30 \\
\hline $\mathbf{D 2}(\boldsymbol{\mu m})$ & 21.39 & 21.13 & 20.61 & 21.13 & 21.04 & 20.78 & 21.01 \\
\hline HV $\left(\mathbf{k g} / \mathbf{m m}^{2}\right)$ & 421 & 429 & 442 & 444 & 435 & 437 & 435 \\
\hline HRC & 43 & 43 & 45 & 45 & 44 & 44 & 44 \\
\hline HK $\left(\mathbf{g}_{\mathbf{f}} / \mathbf{m m}^{\mathbf{2}}\right)$ & 438 & 438 & 466 & 466 & 452 & 452 & 452 \\
\hline
\end{tabular}

* D1 and D2 are the two measured diagonals of the indent, used to calculate the surface area of the indentation.

\subsection{Scanning Electron Microscopy (SEM)}

SEM was conducted on polished surfaces with an accelerating voltage of $20 \mathrm{kV}$, and chemical analysis in the SEM was performed using energy-dispersive spectroscopy (EDS). Figure 6a) shows a secondary electron SEM image with the areas from which EDS spectra were acquired, labeled (1), (2), and (3). The corresponding EDS spectra are displayed in Figure 6b), 6c), and 6d), respectively. The spectrum from region (1) was acquired from a primary dendrite. The measured composition was 98 at.\% Zr, 2 at.\% U (95 wt.\% Zr, 5 wt.\% U), indicating that the dendritic phases consist of $\mathrm{Zr}$ with a small amount of dissolved $\mathrm{U}$. The average composition of the matrix phase, measured from spectra (2) and (3), was 90 at.\% U, 10 at.\% Zr (96 wt.\% U, 4 wt.\% Zr). More accurate measurements of the composition can be obtained with EDS in the TEM, particularly as there appears to be a compositional variation in the matrix phase, evident in the higher-magnification SEM image in Figure 7. 


\section{Lawrence Livermore National Laboratory}

a)
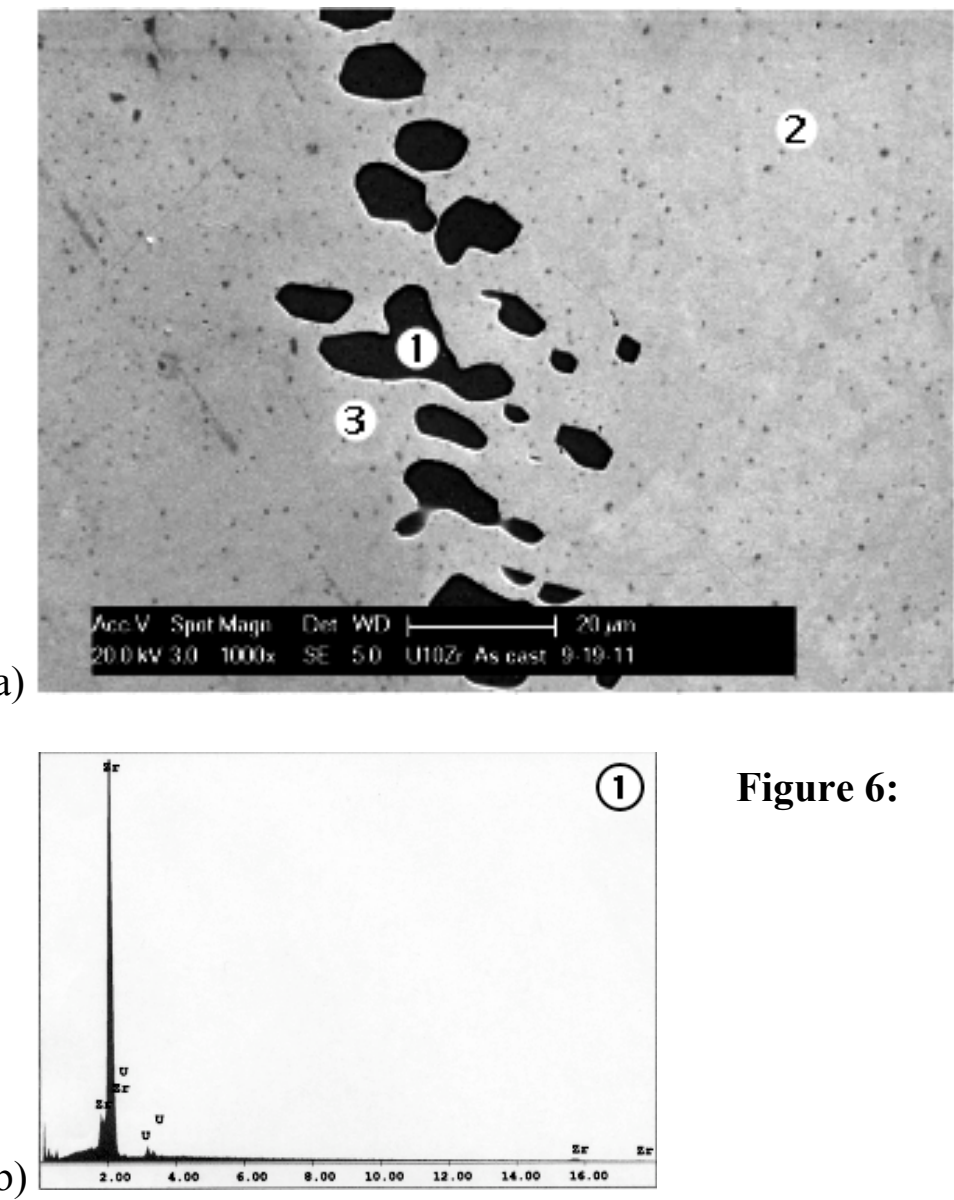

Figure 6: a) SEM image showing regions from which EDS spectra in b), c), and d) were acquired.

(2)

c)
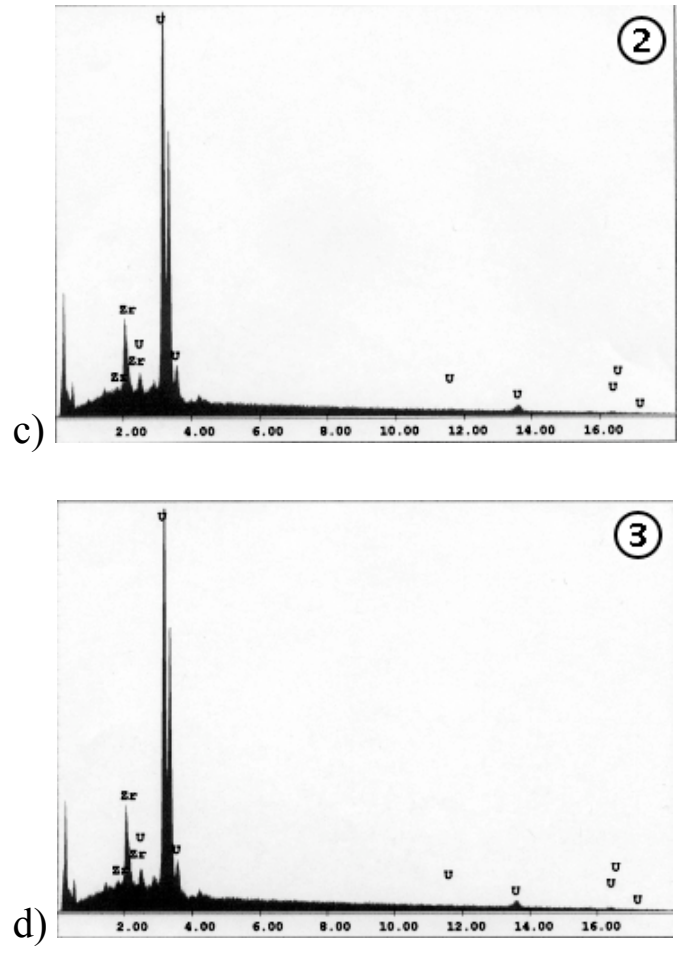

(3) 


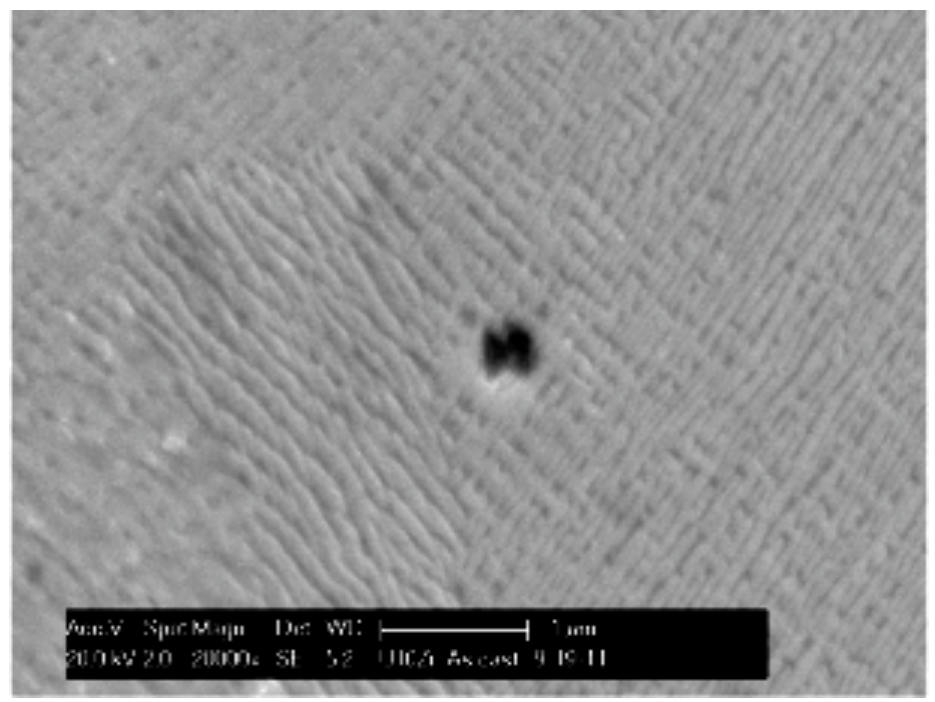

Figure 7: $\quad$ SEM image of a polished surface of the as-cast U-10Zr sample, showing what appears to be a compositional variation in the matrix phase.

\subsection{Transmission Electron Microscopy (TEM)}

TEM specimens from the U-10Zr were prepared. Imaging, diffraction, and compositional analysis using EDS were conducted in a Philips CM300 operating at $300 \mathrm{kV}$. Figure 8a) shows a bright-field image from a primary dendrite with a representative EDS spectrum acquired from the dendrite. The composition of the dendrite was 98 at.\% Zr, 2 at.\% U, which is an average from 5 measured EDS spectra. This composition is consistent with that measured in the SEM. Figure 8b) shows a selected-area diffraction pattern (SADP) acquired from the dendrite along with a simulated diffraction pattern for hexagonal $\mathrm{Zr}$ in the [0001] zone axis. This further shows that the dendrite is $\mathrm{Zr}$ with a small amount of dissolved U. The EDS spectrum shows an O peak, which is likely due a surface oxide on the TEM specimen, evident in the experimental diffraction pattern.

The bright-field images of the matrix phase in Figure 9 show the morphology of the phases that are present at three different magnifications. The microstructure consists of lamellae of alternating phases. The lamellae have an average peak-to-peak spacing of $\sim 75 \mathrm{~nm}$, as measured from line profiles across the bright-field images. EDS reveals that the compositions of the two phases are the U-rich, orthorhombic $\alpha$ phase (dark contrast in the images) and the Zr-rich, intermetallic hexagonal $\delta$ phase (light contrast in the images), as shown in Figure 10. The average compositions of the $\alpha$ and $\delta$ phases, measured in 10 lamellae of each phase, were 97 at.\% U, 3 at.\% Zr and 34 at.\% U, 66 at.\% Zr, respectively. A lever-rule calculation gives 69\% $\alpha$ phase and $31 \% \delta$ phase. This is consistent with the overall composition of the alloy, and reflected by the lamellar widths of the two phases shown in the bright-field images.

It is evident upon inspection of Figure 9a) that the regularly spaced, fine-scale lamellar structure occurs with different orientations due to the fact that the lamellae occur within martensitic-type plates, as seen in the optical micrographs of Figure 4. Attempts to determine whether there is a crystallographic relationship between these plates using electron diffraction have been 
unsuccessful, though metallography indicates there may be a relationship between the martensitic plates and the high-temperature BCC phase. It is also likely, based on examination of the images in Figure 9 and particularly Figure 9f), that the sample has not reached equilibrium, as the interfaces between the two phases appear wavy and curved. These interfaces would likely sharpen and straighten with increased time at temperature.

The crystallography of the $\alpha$ and $\delta$ phases and crystallographic relations between the lamellae has been determined with electron diffraction. Figure 11a) and 11b) show experimental zoneaxis SADPs with simulated diffraction patterns. In all simulated diffraction patterns, blue and red indices correspond, respectively, to the $\alpha$ and $\delta$ phases. The experimental SADPs were acquired from two different grains or martensitic plates, but they are consistent in showing the same orientation relationship (the two orientations in the patterns are $90^{\circ}$ apart). The two orientations shown are:
a): $(001)[010]_{\alpha} \|(\overline{2} 1 \overline{1} 0)[01 \overline{1} 0]_{\delta}$
b): $(100)[010]_{\alpha} \|(0001)[01 \overline{1} 0]_{\delta}$

This also implies the orientation shown in Figure 11c):

$$
\text { c): }(010)[100]_{\alpha} \|(01 \overline{1} 0)[0001]_{\delta}
$$

though this orientation was not observed experimentally. The basal plane of the $\delta$ phase is parallel to the (100) plane of the $\alpha$ phase, the prismatic $(\overline{2} 1 \overline{1} 0)$-type plane ( $a$-plane) of the $\delta$ phase is parallel to the (001) plane of the $\alpha$ phase, and the prismatic (01) 10 -type plane ( $m$-plane) of the $\delta$ phase is parallel to the (010) plane of the $\alpha$ phase.

Figure 12 shows another experimental SADP with its associated simulated diffraction pattern. This pattern was acquired from the same region as that of Figure 11b). The $\alpha$ phase is in the [101] zone axis; the $\delta$ phase is slightly off zone axis, but close to the [101] axis. This is consistent with the zone-axis SADPs shown in Figure 11, and results from the fact that angle between the [100] and [101] directions in the $\alpha$ phase is slightly different than the angle between the [0001] and [10 $\overline{1} 1]$ directions in the $\delta$ phase.

Electron diffraction also reveals the interface plane between the $\alpha$ and $\delta$ phases, shown in Figure 13. From diffraction patterns it was determined that the interface plane consists of the planes $(010)_{\alpha} \|(01 \overline{1} 0)_{\delta}$.

TEM analysis allows determination of the compositions, morphologies, and crystallography of the phases present at a scale that cannot be accessed with X-ray diffraction, optical microscopy, or SEM. The transformation kinetics in the U-Zr system are known to be sluggish [1], and it has proven difficult to detect the presence of both $\alpha$ and $\delta$ phases in low-Zr-content U-Zr alloys $[2,3]$. Under normal casting conditions, only the supersaturated $\alpha$ phase has been observed, though the $\delta$ phase has been characterized using SEM in U-7 wt.\% $\mathrm{Zr}$ alloys that have been annealed for very long times (up to $4400 \mathrm{~h}$ in the $\alpha+\delta$ phase field) [3]. 


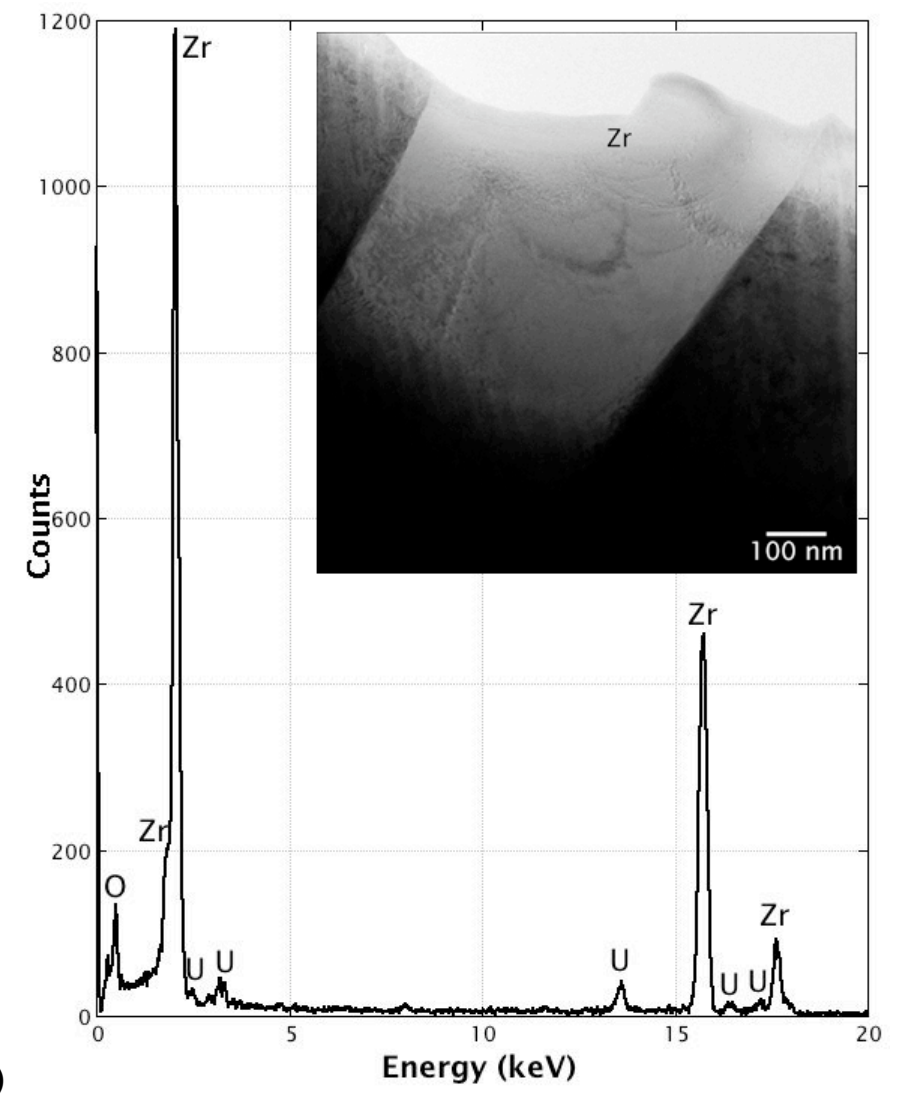

a)
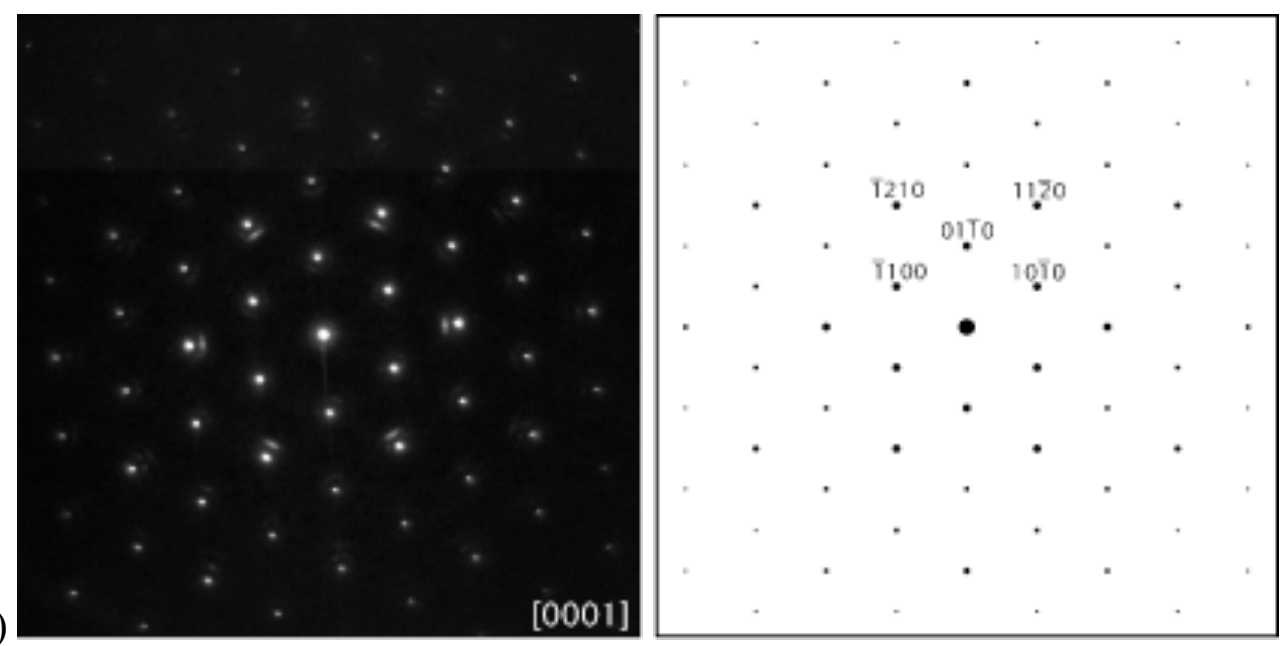

Figure 8: a) Bright-field image of a Zr primary dendrite with representative EDS spectrum.

b) Experimental and simulated diffraction patterns. 
a)

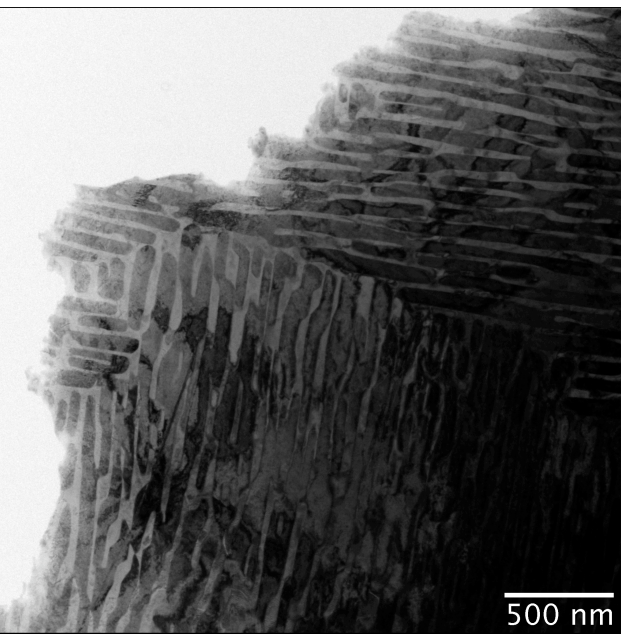

$\overline{500 \mathrm{~nm}}$ b)

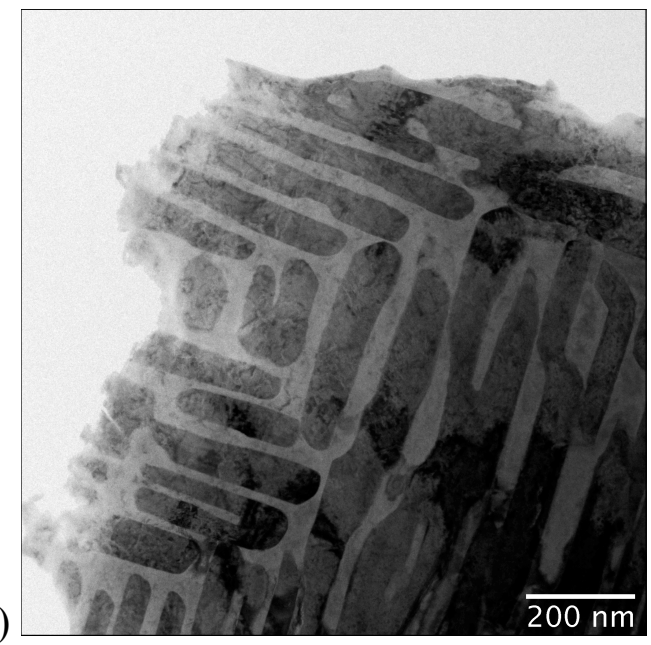

c)

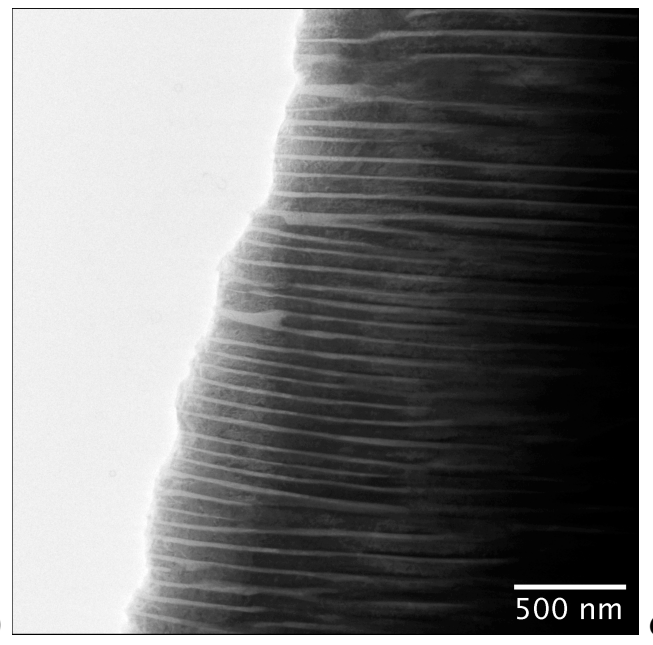

d)

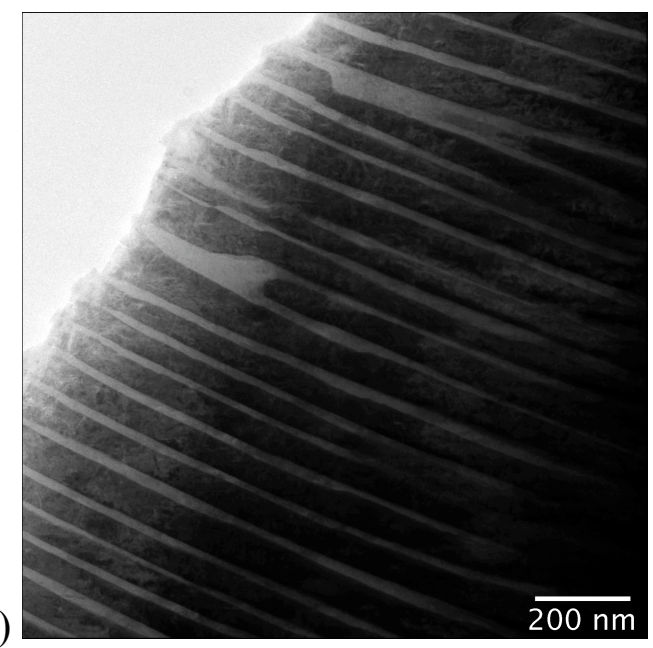

e)

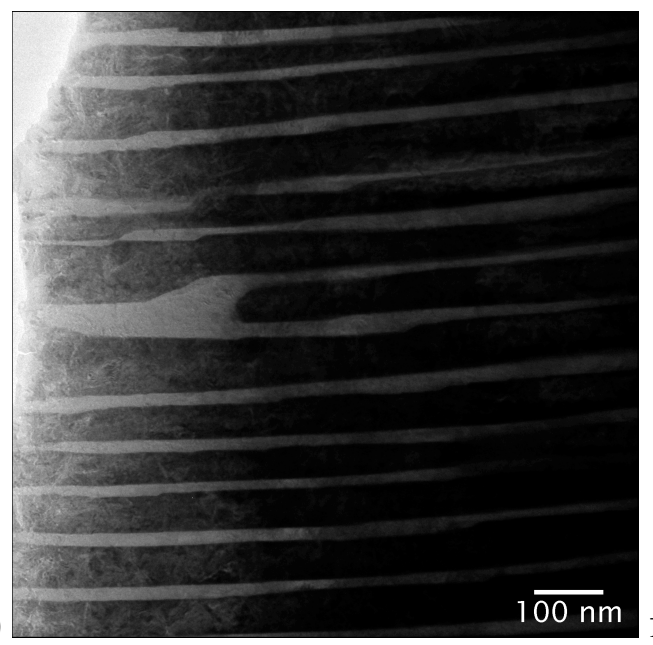

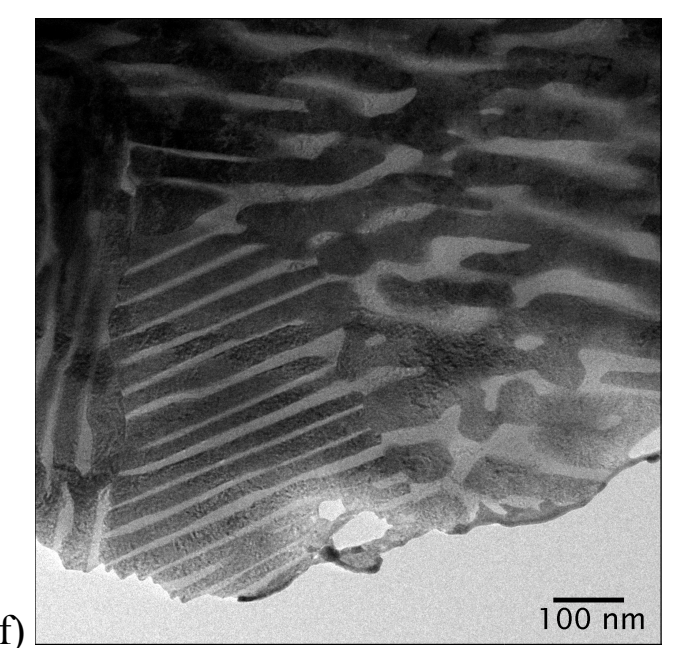

Figure 9: a-f) Bright-field images of the matrix phase in the as-cast U-10Zr specimen. 


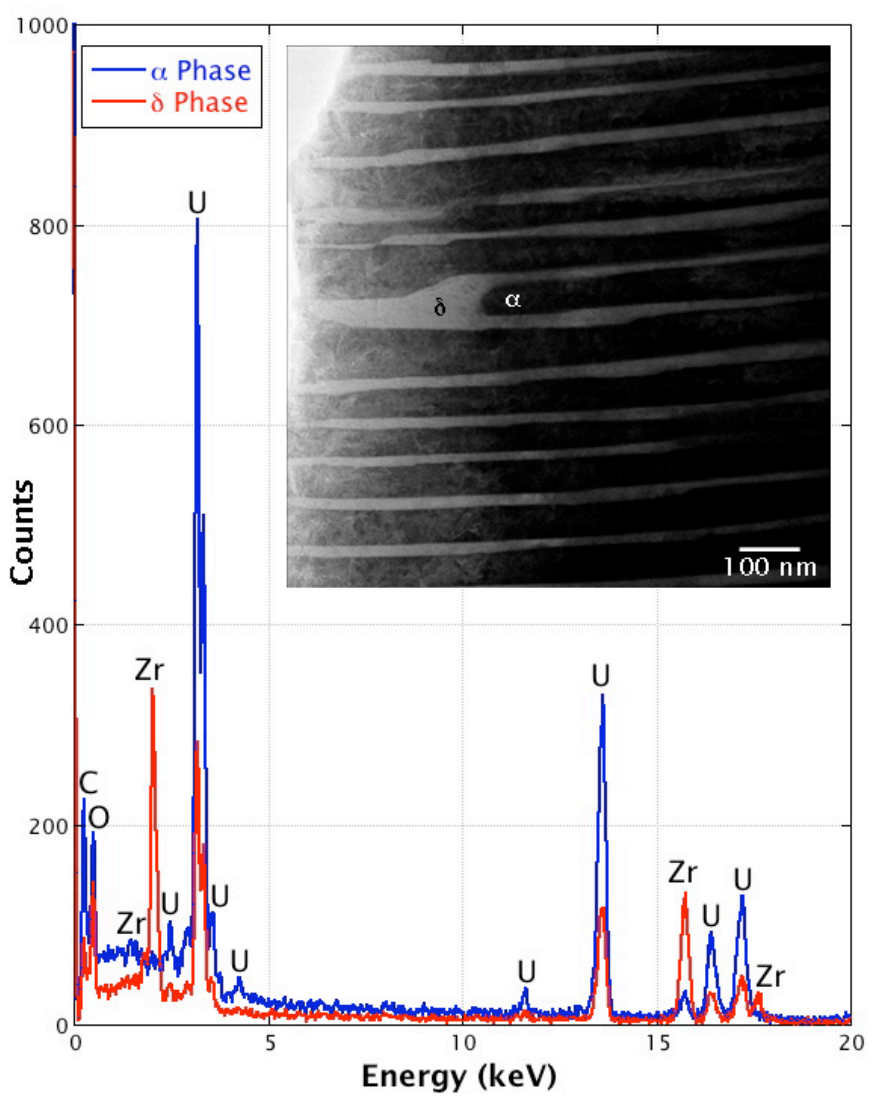

Figure 10: Representative EDS spectra from both $\alpha$ and $\delta$ lamellar phases, with bright-field image inset. 
a)
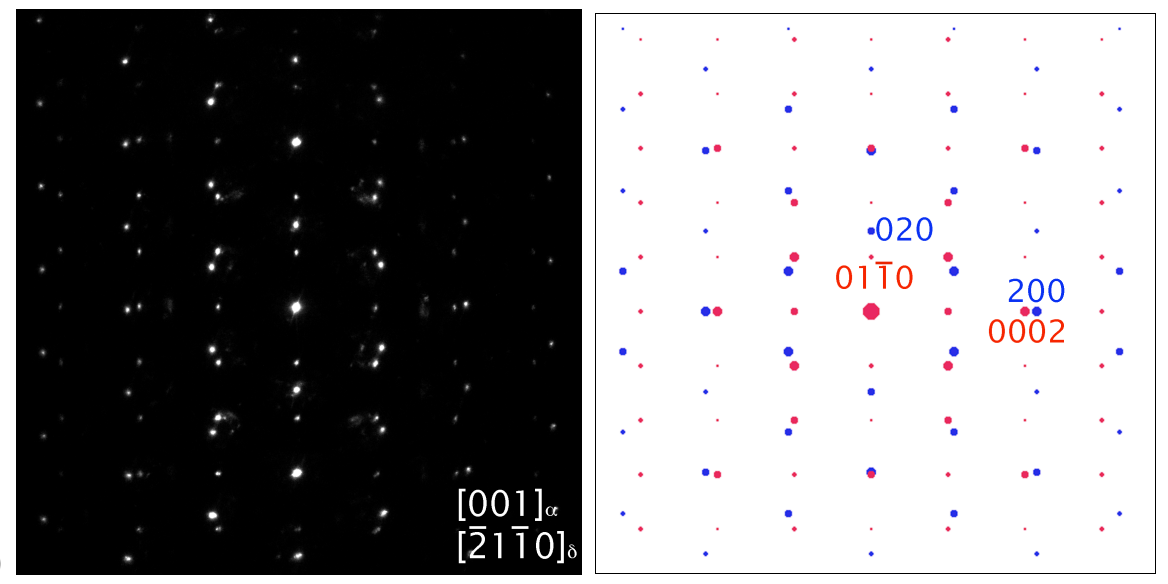

b)
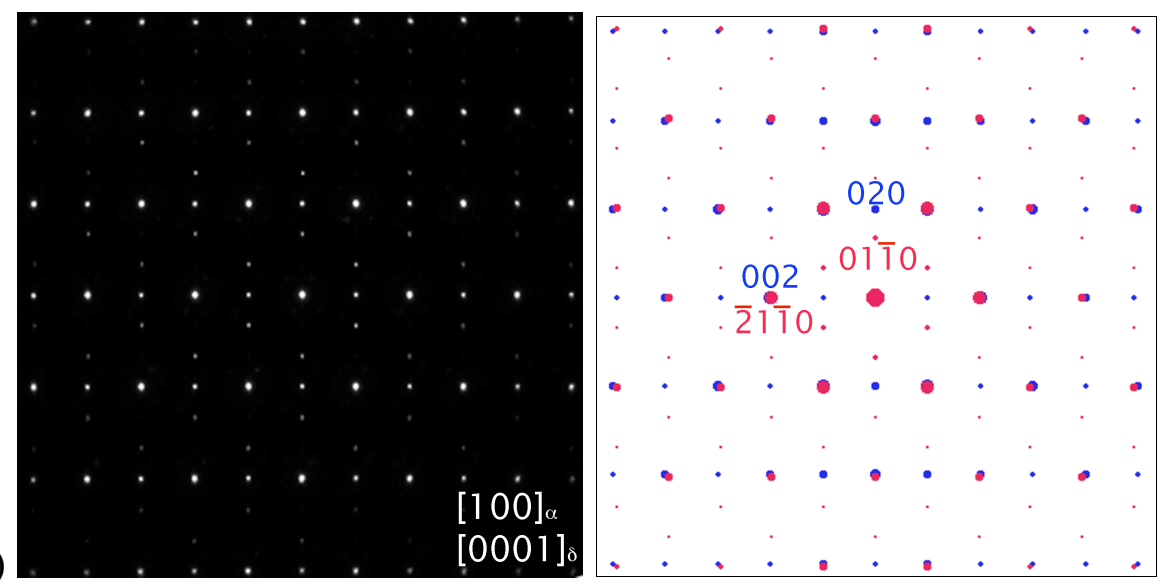

c)

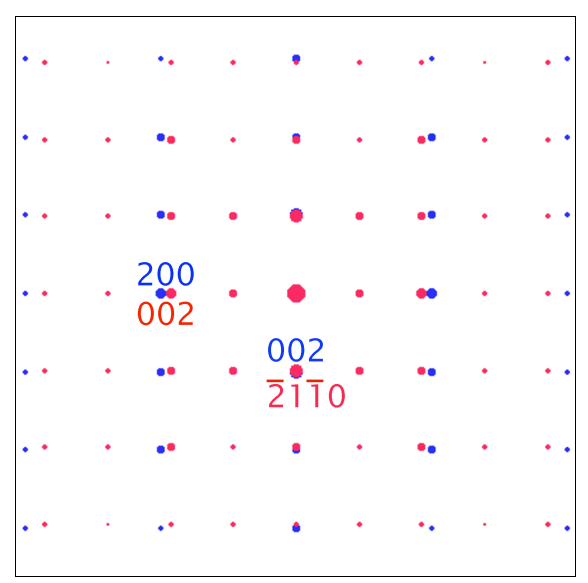

Figure 11: a,b) Experimental and simulated diffraction patterns showing the orientation relationship between the $\alpha$ and $\delta$ phases in two distinct zone axes: a) $(001)[010]_{\alpha} \|(\overline{2} 1 \overline{1} 0)[01 \overline{1} 0]_{\delta}$ and b) (100)[010 $]_{\alpha} \|(0001)[01 \overline{1} 0]_{\delta}$. c) Simulated diffraction pattern showing a third zone axis: $(010)[100]_{\alpha} \|(01 \overline{1} 0)[0001]_{\delta}$. 


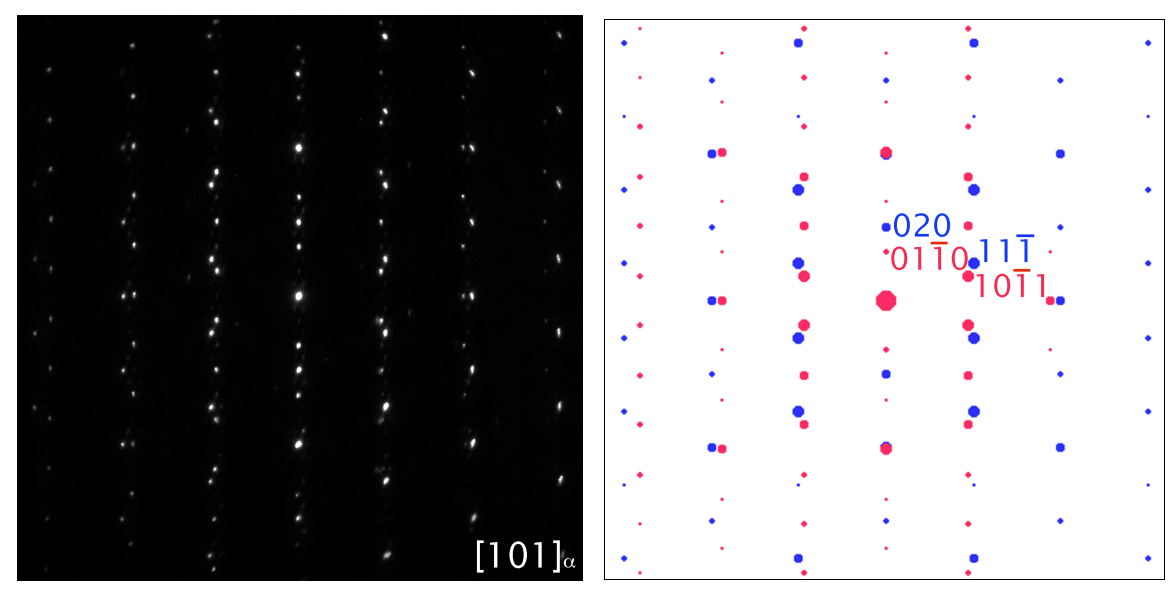

Figure 12: Experimental and simulated diffraction patterns showing the $\alpha$ phase in the [101] zone axis. The $\delta$ phase is slightly off zone axis.

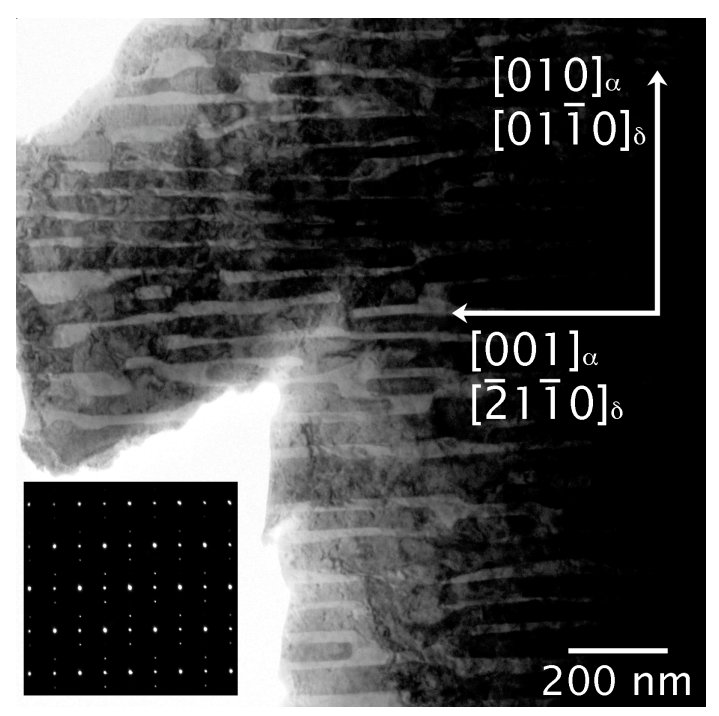

Figure 13: Bright-field TEM image showing the interface plane between the $\alpha$ and $\delta$ phases. The inset diffraction pattern is in the same zone-axis orientation as that of Figure 11b). 


\section{Anneal 1: $900^{\circ} \mathrm{C}$ for $2 \mathrm{~h}$ and Quench}

A section of the as-cast ingot was annealed and then rapidly cooled in an attempt to quench in the high-temperature BCC phase. Annealing was conducted in a vacuum furnace at a pressure of $\sim 10^{-7}$ Torr. The heat treatment consisted of a ramp from room temperature to $900^{\circ} \mathrm{C}$ with a heating rate of $\sim 45{ }^{\circ} \mathrm{C} / \mathrm{min}$, a hold at $900^{\circ} \mathrm{C}$ for $2 \mathrm{~h}$, and a quench to room temperature with a cooling rate of $\sim 6{ }^{\circ} \mathrm{C} / \mathrm{s}$. The quench was achieved by turning off power to the furnace and continuously purging room temperature He gas through the furnace. A TEM specimen was prepared from the annealed sample.

\subsection{Transmission Electron Microscopy (TEM)}

Figure 14 shows bright-field images of the high-temperature annealed and quenched alloy. In Figure 14a), it is evident that there are $\mathrm{Zr}$ dendrites that persist even after this processing. Figures 14b)-d) show the lamellar structure at various magnifications. The lamellae have an average peak-to-peak spacing of $\sim 38 \mathrm{~nm}$, as measured from line profiles across the bright-field images (roughly half that of the as-cast alloy). EDS results reveal that the average compositions of the two phases are $\alpha: 96$ at.\% U, 4 at.\% Zr; $\delta: 33$ at.\% U, 67 at.\% Zr, the same as those measured in the as-cast alloy. Figure 15 shows representative spectra from the $\alpha$ and $\delta$ phases. The only difference between the as-cast and annealed specimens is the scale of the lamellar structure.

These results show that longer anneals may be necessary to fully homogenize the alloy, as well as more rapid cooling rates to quench in the high-temperature $\mathrm{BCC}$ phase. 


\section{Lawrence Livermore National Laboratory}
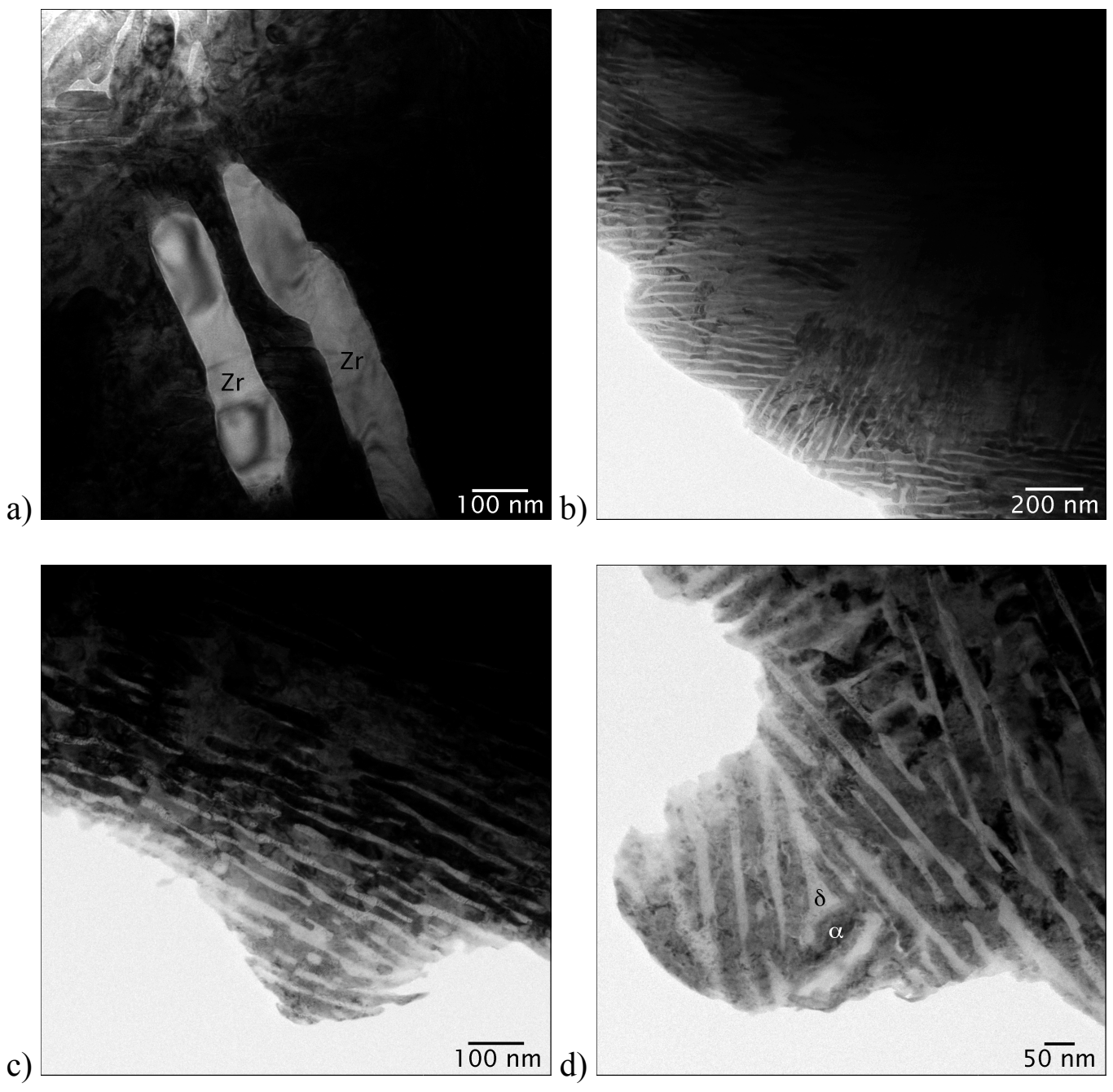

Figure 14: Bright-field TEM images of the annealed U-Zr alloy showing a) persisting $\mathrm{Zr}$ dendrites and $b-d)$ the lamellar structure consisting of the $\alpha$ and $\delta$ phases. 


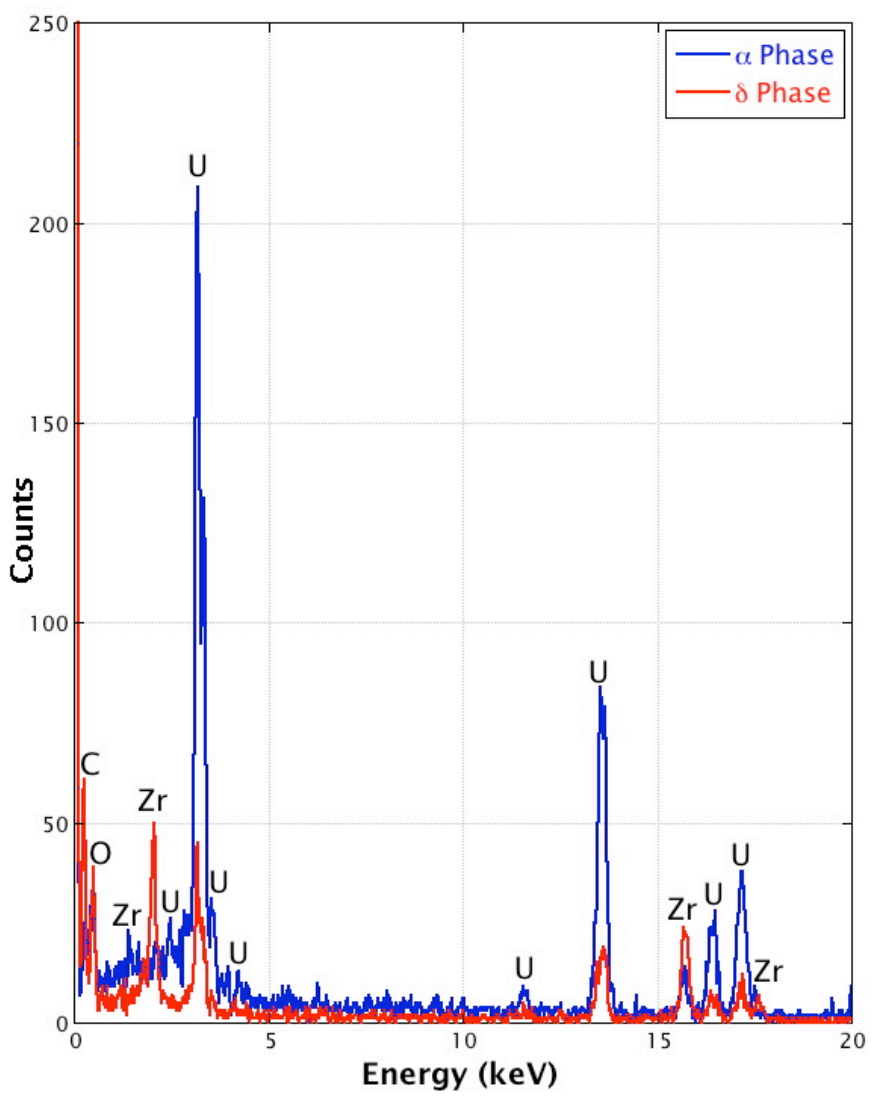

Figure 15: Representative EDS spectra from the $\alpha$ and $\delta$ lamellar phases. 


\section{Lawrence Livermore National Laboratory}

\section{References}

[1] Ogata, T. et al. "Interdiffusion in uranium-zirconium solid solutions," J. Nucl. Mater. 232 (1996) 125-30.

[2] Basak, C.H. et al. "Phase transformations in U-2 wt\% Zr alloy," J. Alloys Compd. 471 (2009) 544-52

[3] Basak, C.H. "Microstructural evaluation of U-rich U-Zr alloys under near-equilibrium condition," J. Nucl. Mater. 416 (2011) 280-87. 